\title{
Acute renal failure complicating cardiopulmonary bypass surgery
}

\author{
S P A RIGDEN, T M BARRATT, M J DILLON, M DE LEVAL, AND J STARK \\ Department of Nephrology, Institute of Child Health, University of London, and Thoracic Unit, \\ Hospital for Sick Children, London
}

SUMMARY Acute renal failure developed in $24(5.3 \%)$ of 456 children undergoing cardiopulmonary bypass surgery during a 2 -year period. It was more common in younger children, in those with complex cardiac lesions, and in those with long overall bypass times. Fourteen $(58 \%)$ recovered renal function; renal failure was responsible for death in only two. Early vigorous peritoneal dialysis is advocated after cardiopulmonary bypass surgery if there is oliguria $(\leqslant 1.0 \mathrm{ml}$ urine $/ \mathrm{kg}$ per hour) resistant to volume repletion, dopamine infusion and diuretics, intractable fluid overload, or hyperkalaemia.

Acute renal failure (ARF) has long been known as an important complication of cardiopulmonary bypass surgery (CPBS) and carries a poor prognosis. ${ }^{1}$ The incidence of postoperative ARF differs in reported series, being influenced by the criteria used for its definition and the patient population studied, as well as by intrinsic variation. Chesney et $a .^{2}{ }^{2}$ observed ARF in $20(8.1 \%)$ of 248 infants undergoing cardiac surgery: 6 were dialysed and $13(65 \%)$ died. Bhat et al. ${ }^{3}$ studied 490 adults undergoing open heart surgery and identified 21 $(4.3 \%)$ in whom the plasma creatinine concentration exceeded $5 \mathrm{mg} / 100 \mathrm{ml}(440 \mu \mathrm{mol} / \mathrm{l}) ; 11$ were dialysed and $14(67 \%)$ died.

We have formed the impression that ARF remains a major problem after CPBS in children; perhaps advances in surgical technique have resulted in complex operations being performed on sick infants hitherto deemed inoperable. We therefore embarked on a prospective study of the incidence of ARF in children undergoing CPBS in order to investigate the factors which predispose to ARF and its outcome with treatment.

\section{Patients and methods}

Four hundred and fifty-six children underwent CPBS in the thoracic unit of The Hospital for Sick Children in 1978-79. The unit is a national and international referral centre for children with congenital heart disease and therefore receives a high proportion of complex cases.

CPBS was carried out under hypothermia using core cooling; surface cooling was also used in some sick infants. The pump was primed with citratephosphate-dextrose anticoagulated whole blood and Hartmann's solution to give a haematocrit on bypass of about $0 \cdot 3$. Flow rates of $2.41 / \mathrm{m}^{2}$ surface area were used with periods of reduced flow and circulatory arrest as appropriate for the surgery undertaken. All children had urinary catheters in situ during surgery and during at least the first postoperative day. Gentamicin ( $2 \mathrm{mg} / \mathrm{kg} 8$ hourly) was given prophylactically for 5 days to nearly every infant and to older children if surface prosthetic material had been used, unless renal impairment supervened. Frusemide $(0.5-5 \mathrm{mg} / \mathrm{kg}$ intravenously) was administered only if a diuretic was clinically indicated.

We have not attempted to distinguish between oliguria arising from poor renal perfusion and established acute tubular necrosis; in this complex clinical state in which diuretics have been administered and many other factors are operative, such distinction is often difficult and is of little practical importance as the outcome is determincd by the inability of the kidney to fulfil its excretory role whatever the underlying pathogenesis. In this study all children who developed oliguria (the production of $\leqslant 1.0 \mathrm{ml}$ urine $/ \mathrm{kg}$ per hour averaged over 4 hours) resistant to volume repletion, dopamine infusion, and diuretics (frusemide $5 \mathrm{mg} / \mathrm{kg}$ intravenously), or hyperkalaemia (plasma potassium $>6.0 \mathrm{mmol} / \mathrm{l}$ ), or increasing uraemia (urea $>40 \mathrm{mmol} / \mathrm{l}$ ) were defined as having ARF and were dialysed.

Peritoneal dialysis was performed using standard paediatric dialysis catheters and commercially 
available lactate dialysis solutions unless a lactic acidosis was suspected, in which case a bicarbonate dialysis solution was substituted.

\section{Results}

Twenty-four $(5.3 \%)$ of the 456 children developed ARF after CPBS (Table 1).

Risk factors for ARF. There was an increased incidence of ARF in younger children $\left(\chi^{2}=\right.$ 27: $P<0.001$; Table 2). Six of the 21 neonates operated on developed ARF: all had undergone emergency surgery, with 4 having had angiocardiography performed in the immediate preoperative period. Three of the 6 recovered renal function but only 2 ultimately survived. Of the 10 infants with ARF aged between 29 days and 1 year, 6 had undergone emergency surgery, 5 of whom required preoperative assisted ventilation because of severe cardiac failure; 7 had failed to thrive and were considerably below the 3rd centile for age; 6 recovered renal function but only 5 survived. All 8 children over age 1 year had elective operations and only 3 died.

The plasma creatinine or urea concentration was slightly raised before operation in 5 children (Cases $2,7,11,13$, and 15 ); in the remainder it was normal.

The individual diagnoses and operations performed in the children with ARF are shown in Table 1. The diagnostic groupings in Table 3 show a greater frequency of ARF in cyanotic than in acyanotic conditions, with the highest incidence and mortality in the miscellaneous group of 33 children with rare complex lesions.

Long overall bypass time (defined in this paper to include periods of circulatory arrest) is significantly associated with ARF $\left(\chi^{2}=12 ; \mathrm{P}<0.05\right.$; Table 4$)$. There were only $5(2.1 \%)$ cases of ARF in the 238 children with overall bypass times shorter than 90 minutes compared with $19(9.7 \%)$ in the 196 with overall bypass times longer than 90 minutes.

All but one of the patients dialysed required inotropic support with dopamine, adrenaline, or isoprenaline, or a combination of these drugs because of low cardiac output; in 15 it was necessary

Table 2 Effect of age on incidence and mortality of acute renal failure in 456 children

\begin{tabular}{llccll}
\hline Age & $\begin{array}{l}\text { Total } \\
\text { no of } \\
\text { children }\end{array}$ & \multicolumn{4}{c}{ Acute renal failure } \\
\cline { 3 - 6 } & No & $\begin{array}{c}\% \text { of } \\
\text { total }\end{array}$ & $\begin{array}{l}\text { Hospital } \\
\text { deaths }\end{array}$ & $\%$ \\
\hline 28 days & 21 & 6 & 29 & 4 & 67 \\
29 days-1 year & 131 & 10 & 8 & 5 & 50 \\
$>1$ year & 304 & 8 & 3 & 3 & 38 \\
\hline
\end{tabular}

Table 3 Effect of diagnosis on incidence and mortality of acute renal failure in 456 children

\begin{tabular}{|c|c|c|c|c|c|}
\hline \multirow[t]{2}{*}{ Diagnosis } & \multirow{2}{*}{$\begin{array}{l}\text { Total } \\
\text { no of } \\
\text { children }\end{array}$} & \multicolumn{4}{|c|}{ Acute renal failure } \\
\hline & & No & $\begin{array}{l}\% \text { of } \\
\text { total }\end{array}$ & $\begin{array}{l}\text { Hospital } \\
\text { deaths }\end{array}$ & $\%$ \\
\hline $\begin{array}{l}\text { PS PA TA } \\
\text { VSD ASD APW }\end{array}$ & 39 & 0 & 0 & 0 & - \\
\hline DORV (high flow) & 102 & 1 & 1 & 1 & 100 \\
\hline $\begin{array}{l}\text { MVD AVD } \\
\text { TGA + VSD + LVOTO }\end{array}$ & 34 & 1 & 3 & 0 & \\
\hline Mayo FT DORV + PS & 75 & 4 & 5 & 1 & 25 \\
\hline $\begin{array}{l}\text { TGA } \\
\text { TAPVD A-V defect }\end{array}$ & 113 & 7 & 6 & 3 & 43 \\
\hline Truncus I & 60 & 4 & 7 & 2 & 50 \\
\hline Miscellaneous & 33 & 7 & 21 & 5 & 71 \\
\hline
\end{tabular}

PA $=$ pulmonary atresia $;$ TA $=$ tricuspid atresia; $\mathbf{A P W}=$ aortopulmonary window; $\mathbf{M V D}=$ mitral valve disease; AVD $=$ aortic valve disease; Mayo = Mayo syndrome; FT $=$ Fallot's tetralogy; A-V defect $=$ atrioventricular canal defect.

See Table 1 for remaining abbreviations.

Table 4 Effect of overall bypass plus circulatory arrest time on incidence and mortality of acute renal failure in 434 children*

\begin{tabular}{|c|c|c|c|c|c|}
\hline \multirow[t]{2}{*}{ Time (min) } & \multirow{2}{*}{$\begin{array}{l}\text { Total } \\
\text { number } \\
\text { of } \\
\text { children }\end{array}$} & \multicolumn{4}{|c|}{ Acute renal failure } \\
\hline & & No & $\begin{array}{l}\% \text { of } \\
\text { total }\end{array}$ & $\begin{array}{l}\text { Hospital } \\
\text { deaths }\end{array}$ & $\%$ \\
\hline$<30$ & 17 & 0 & 0 & 0 & - \\
\hline $31-60$ & 77 & 1 & 1 & 1 & 100 \\
\hline $61-90$ & 144 & 4 & 3 & 4 & 100 \\
\hline $91-120$ & 113 & 10 & 9 & 6 & 60 \\
\hline$>120$ & 83 & 9 & 11 & 2 & 22 \\
\hline
\end{tabular}

* Not recorded in 22.

to start this support in the operating theatre because of poor post-bypass haemodynamics. All but 3 of the children received gentamicin prophylactically. There was no case of septicaemia among the children with ARF. Thrombocytopenia occurred in all children with ARF, the lowest recorded counts in each individual ranging from 3 to $42 \times 10^{9} / 1$.

Peritoneal dialysis-indications, duration, and complications. The indications for dialysis are given in Table 5; in some children more than one indication was present. Fluid overload was assessed on a scale $1-3+: 1+$ implying mild peripheral oedema only, $2+$ gross peripheral oedema and mild pulmonary oedema, and $3+$ severe pulmonary oedema with obvious increase in atrial pressures. Fluid overload was particularly a problem in the neonates, in 4 of whom (Cases 2-5) it was a major indication for dialysis; even though urine flow rates exceeded $1 \mathrm{ml} / \mathrm{kg}$ per hour in 3 of them, overload persisted because of the need to maintain parenteral fluid intake as a vehicle for catecholamines and other drugs. Six of the children were hyperkalaemic and 
Table 5 Indications for dialysis related to age

\begin{tabular}{lllll}
\hline Age & $\begin{array}{l}3+\text { fluid } \\
\text { overload }\end{array}$ & $\begin{array}{l}\text { Plasma K+ } \\
>6.0 \mathrm{mmol}^{+} \mathrm{l}\end{array}$ & $\begin{array}{l}\text { Urine flow } \\
<1 \mathrm{ml} / \mathrm{kg} \\
\text { per hour }\end{array}$ & $\begin{array}{l}\text { Plasma urea } \\
>40 \mathrm{mmol} / \mathrm{l}\end{array}$ \\
\hline $\begin{array}{c}<2 \text { days } \\
29 \text { days }-\end{array}$ & 4 & 1 & 3 & 0 \\
1 year & 3 & 2 & 6 & 0 \\
$>1$ year & 2 & 3 & 6 & 1 \\
\hline
\end{tabular}

15 were oliguric. In only one child (Case 21) was dialysis undertaken solely because of a rising plasma urea concentration.

The time interval between operation and the start of dialysis ranged from 3 (Case 4) to 80 (Case 21) hours with a mean value of 16 hours for the neonates, 26 hours for the infants, and 52 hours for the older children. Nine children, all younger than 1 year, were dialysed within the first 24 hours after CPBS and 7 died, compared with only 5 deaths among the 15 children dialysed later $(P<0.05$ exact test, Table 6).

All children were treated by continuous peritoneal dialysis. In one (Case 19), insertion of the catheter was followed by intraperitoneal bleeding that led to laparotomy. Four developed peritoneal infections. Four others were complicated by lactic acidosis; one (Case 18) responded to bicarbonate dialysis, but for the other 3 it was a terminal event. Two neonates became hyperglycaemic during dialysis and were treated with insulin.

Duration of dialysis varied from 1 hour (Case 23) to 21 days (Case 6). Seven children were dialysed for shorter periods than 24 hours, 5 of them dying within that time. Eight children were dialysed for periods of $24-48$ hours, with 3 dying on dialysis and 5 recovering complete renal function. The remaining 9 children were dialysed for periods longer than 48 hours, with only 1 child in this group dying on dialysis.

Outcome. Nine children died on peritoneal dialysis: 8 of these deaths were attributable to cardiac causes and the ninth (Case 23) was probably due to hyperkalaemia. One (Case 6) never recovered renal func-

Table 6 Effect of time interval from operation to dialysis on recovery of renal function

\begin{tabular}{|c|c|c|c|c|}
\hline \multirow{2}{*}{$\begin{array}{l}\text { Time between } \\
\text { operation and } \\
\text { peritoneal dialysis } \\
\text { (hours) }\end{array}$} & \multicolumn{3}{|l|}{ Age } & \multirow[t]{2}{*}{ Total } \\
\hline & $<28$ days & 29 days-1 year & $>1$ year & \\
\hline $\begin{array}{r}<24 \\
25-48 \\
>48\end{array}$ & $\begin{array}{l}5(3) \\
1 \\
0\end{array}$ & $\begin{array}{l}4(2) \\
5(1) \\
1(1)\end{array}$ & $\begin{array}{l}0 \\
5(3) \\
3\end{array}$ & $\begin{array}{r}9(5) \\
11(4) \\
4(1)\end{array}$ \\
\hline
\end{tabular}

N!ımber of children who did not recover renal function shown in brackets. tion, dying of uraemia after dialysis had been stopped. Two others died during the same hospital admission having recovered renal function, one from pulmonary hypertension (Case 1) and the other (Case 11) from Candida septicaemia. The hospital mortality for the entire group was therefore $50 \%$. However, of the survivors 3 had some neurological deficit and 3 others died after further cardiac surgery, so that only $6(25 \%)$ ultimately survived unscathed.

\section{Discussion}

Acute renal failure complicating CPBS is generally multifactorial in aetiology. ${ }^{24}$ We have examined the relative roles of various risk factors which may contribute to the pathogenesis of ARF in children.

Cardiac diagnosis. The incidence of postoperative ARF varies in different diagnostic categories (Table 3). Lesions may carry a high risk because (1) they are complex and therefore require long overall bypass times for complete surgical correction-for example complex transposition of the great arteries; (2) they cause severe cyanosis with tissue hypoxia and acidosis-for example transposition of the great arteries, Fallot's tetralogy; (3) they present in early infancy with intractable heart failure-for example truncus arteriosus type I, atrioventricular canal defect, or (4) they have a combination of these features-for example total anomalous pulmonary venous drainage.

Age at operation. There is a significantly increased risk of postoperative ARF in the neonates $(29 \%)$ and to a lesser extent in the infants $(8 \%$, Table 2$)$. There are several possible reasons for this which may be additive. CPBS is only undertaken in neonates as a life saving measure if other treatment, medical or surgical, is ineffective. This is therefore, the sickest group of patients subjected to surgery and would be expected to have the highest mortality and incidence of ARF. The normal neonatal kidney has a reduced glomerular filtration rate compared with that of a child or adult, even when calculated on a body surface area basis. ${ }^{5}$ Renal blood flow is also reduced and preferentially distributed to the juxta-medullary glomeruli at the expense of the outer cortical areas. ${ }^{6} \mathrm{~A}$ similar situation of reduced renal blood flow with outer cortical hypoperfusion has been demonstrated after ischaemia in many experimental models of ARF. ${ }^{7}$ The neonatal kidney may be susceptible to insults that would not cause progression to ARF in the fully mature kidney.

Overall bypass time. We found, in common with studies from adult centres, a correlation between the 
duration of cardiopulmonary bypass and circulatory arrest with the incidence of ARF. ${ }^{348}$ We have not attempted to distinguish in this report between the detrimental effects of circulatory arrest and bypass. There was an inverse relationship between overall bypass time and age in the children with ARF, with the mean bypass time being 90 minutes in the neonates, 114 minutes in the infants, and 129 minutes in the older children. This suggests that age or preoperative condition is a more potent determinant of postoperative renal function than bypass time alone.

Preoperative factors. Progressive cardiac failure or severe cyanosis were indications for emergency surgery in 12 children. Cardiac failure, hypoxia, and acidosis may each cause a reduction in renal cortical blood flow similar to that seen in the early stages of ARF and could therefore facilitate the development of ARF. Angiocardiography, which was performed in 5 children in the immediate preoperative period, has also been shown to reduce cortical perfusion and the hypertonic dye used can cause medullary necrosis. ${ }^{9}$

Postoperative factors. All except one child required inotropic support postoperatively for low cardiac output. Despite the use of dopamine, adrenaline, isoprenaline, or combinations of these drugs, often in large doses, cardiac output was not always restored to an acceptable level. Fifteen children developed the 'low output syndrome' after cardiopulmonary bypass had stopped and required immediate catecholamine support. Bhat et $\mathrm{al}^{3}{ }^{\mathbf{3}}$ found a positive correlation between the 'low output syndrome' and subsequent development of ARF, and our data support this view.

Twenty-one children received gentamicin as a prophylactic antibiotic until the time ARF was suspected, thereby raising the question of the possible contribution of gentamicin nephrotoxicity to the pathogenesis of ARF ${ }^{10}$ However, in a controlled trial of 40 children undergoing CPBS (to be reported in full elsewhere), we did not find impairment of renal function postoperatively to be associated with gentamicin.

Thrombocytopenia was common to all 24 children, with lowest recorded individual platelet counts in the range of 3 to $42 \times 10^{9} / 1$ (mean $\left.22 \times 10^{9} / 1\right)$, whereas in a series of 36 children, who did not develop ARF and who were studied daily for 5 days postoperatively, the lowest recorded platelet counts ranged from 12 to $136 \times 10^{9} / 1$ (mean $\left.55 \times 10^{9} / 1: \mathrm{P}<0.001\right)$. CPBS is a potent cause of acute thrombocytopenia in the immediate postoperative period with counts spontaneously return- ing to normal within 24 hours of bypass. ${ }^{11}$ However, in the children who developed ARF, thrombocytopenia was more severe and prolonged, raising the possibility of platelet consumption.

Peritoneal dialysis. Of the 9 children dialysed for severe fluid overload, only 3 were oliguric, but in the others, despite inotropic support and large doses of diuretics, urine production was insufficient to reverse the state of fluid overload and increasing pulmonary oedema. Three of these 9 patients were also hyperkalaemic, but 4 of them were neither hyperkalaemic nor oliguric and it could be argued that dialysis was unnecessary in them. Two of them (Cases 4 and 8) died and the condition of the other 2 (Cases 5 and 9), who were both requiring maximal inotropic support, improved rapidly with the removal of excess fluid. Cardiac output improved, urine flow increased, and the doses of inotropes could be reduced. In these 2 patients renal failure was clearly secondary to poor myocardial function, but this improved when the severe fluid overload was relieved by peritoneal dialysis. Six children had plasma potassium concentrations of $\geqslant 6.0 \mathrm{mmol} / \mathrm{l}$, a level considered to be an absolute indication for dialysis because of the rapidity with which plasma potassium can rise in postoperative catabolic states, but only 3 of these children were oliguric.

Outcome. The mortality rate of $50 \%$ for children dialysed for ARF after CPBS is a pronounced improvement on our previous figure of $87 \%$ in $1973,{ }^{12}$ and compares favourably with recently reported adult series. Abel et al. ${ }^{8}$ reported no survivors among 15 patients who required dialysis; in Bhat's series ${ }^{3}$ there were 2 survivors from 11 dialysed patients; Hodson reported 3 survivors of 11 children treated with haemodialysis. ${ }^{13}$ It is however difficult and may be misleading to try to compare series because of the problems of case selection and definition of ARF.

ARF, while remaining a serious complication of CPBS, is not irrecoverable with early and vigorous treatment. As a result of our experience, we strongly advocate peritoneal dialysis in any child who becomes oliguric (production of $\leqslant 1 \mathrm{ml}$ urine $/ \mathrm{kg}$ per hour) or hyperkalaemic (plasma potassium $\geqslant 6.0$ $\mathrm{mmol} / \mathrm{l}$ ) in the postoperative phase after CPBS. We also believe that dialysis may be beneficial in children, who by strict definition are not oliguric, but who despite maximal doses of diuretics and inotropic support, are unable to produce sufficient urine to prevent the serious consequences of fluid overload. In this series $58 \%$ of patients recovered renal function and ARF was the direct cause of death in only 2 patients. 
Presented in part at the World Congress of Paediatric Cardiology, London, June 1980 and at the Fifth International Symposium on Pediatric Nephrology, Philadelphia, October 1980.

S P A R was supported by grants from the National Kidney Research Fund of Great Britain and the Kidney Research Aid Fund.

\section{References}

1 Ogg C S, Cameron J S. Cardiovascular surgery and the kidney. Guy's Hospital Reports 1969; 118: 85-103.

2 Chesney R W, Kaplan B S, Freedom R M, Haller J A, Drummond $\mathrm{K} N$. Acute renal failure: an important complication of cardiac surgery in infants. $J$ Pediatr 1975; 87: 381-8.

3 Bhat J G, Gluck M C, Lowenstein J, Baldwin D S. Renal failure after open heart surgery. Ann Intern Med 1976; 84: 677-82.

4 Hilberman M, Myers B D, Carrie B J, Derby G, Jamison R L, Stinson E B. Acute renal failure following cardiac surgery. J Thorac Cardiovasc Surg 1979; 77: 880-8.

5 Spitzer A. Renal physiology and functional development. In: Edelmann $\mathbf{C} \mathbf{M}, \mathrm{Jr}$, ed. Pediatric kidney disease. Boston: Little Brown, 1978: 25-127.

- Spitzer A, Brandis M. Superficial nephron and total kidney glomerular filtration rate during development (abstract). Pediatr Res 1972; 6: 416.

7 Daugharty T M, Brenner B M. Reversible hemodynamic defect in glomerular filtration rate after ischemic injury. Am J Physiol 1975; 228: 1436-9.

8 Abel R M, Buckley M J, Austen W G, Barnett G O, Beck C H, Jr, Fischer J E. Acute post-operative renal failure in cardiac surgical patients. J Surg Res 1976; 20: 341-8.

9 Gruskin A B, Oetliker O H, Wolfish N W, Gootman N L, Bernstein J, Edelmann C M, Jr. Effects of angiography on renal function and histology in infants and piglets. J Pediatr 1970; 76: 41-8.

10 Falco F G, Smith H M, Arcieri G M. Nephrotoxicity of aminoglycosides and gentamicin. J Infect Dis 1969; 119: 406-9.

11 de Leval M, Hill J D, Mielke C H, Macur M F, Gerbode F. Blood platelets and extra-corporeal circulation. Kinetic studies on dogs on cardiopulmonary bypass. $J$ Thorac Cardiovasc Surg 1975; 69: 144-51.

12 Barratt T M. Post-operative renal complications of children with congenital heart disease. Proc Ass Eur Paediatr Cardiol 1973; 9: 54-6.

13 Hodson E M, Kjellstrand C M, Mauer S M. Acute renal failure in infants and children: outcome of 53 patients requiring hemodialysis treatment. $J$ Pediatr 1978; 93: 756-61.

Correspondence to Professor T M Barratt, Department of Nephrology, Institute of Child Health, 30 Guilford Street, London WC1N 1EH.

Received 6 August 1981 